\title{
A unique case of a myelodysplastic/myeloproliferative neoplasm with distinct histiocytic and dendritic cell outgrowths
}

\author{
Jamie Macagba Slade • Sherri Korman • Basharath Khan • \\ Shriram M. Jakate • Vijaya B. Reddy • Ira J. Miller
}

Received: 2 July 2014 / Accepted: 12 February 2015 / Published online: 5 March 2015

(C) Springer-Verlag Berlin Heidelberg 2015

\begin{abstract}
Erdheim-Chester disease (ECD) and Langerhans cell histiocytosis $(\mathrm{LCH})$ are rare histiocytic disorders with multisystem involvement. Both are considered distinct entities with characteristic clinical, radiological, and pathological features. A limited number of cases have been reported of patients with ECD in association with LCH. We report a case, for the first time to our knowledge, of a patient with ECD, coexisting $\mathrm{LCH}$, a third histiocytosis of less defined lineage, and a myelodysplastic/myeloproliferative neoplasm (MDS/ MPN).
\end{abstract}

Keywords Erdheim-Chester disease $\cdot$ Langerhans cell histiocytosis $\cdot$ Myelodysplastic/myeloproliferative neoplasm

\section{Introduction}

Histiocytosis refers to a spectrum of diseases characterized by the excessive proliferation of histiocytes which often present with multisystem involvement. Broadly, the histiocytic disorders can be classified into the Langerhans cell histiocytoses and non-Langerhans cell histiocytoses based on cell lineage. The Langerhans histiocytoses comprise a spectrum of diseases formerly known as Hand-Schuller-Christian disease (multifocal, unisystemic form), Letterer-Siwe disease (multifocal, multisystemic form), eosinophilic granuloma (unifocal form), and Hashimoto-Pritzker disease (congenital self-healing reticulohistiocytosis) [1]. The non-Langerhans histiocytoses include juvenile xanthogranuloma, Rosai-Dorfman disease

J. M. Slade $(\triangle) \cdot$ S. Korman • B. Khan · S. M. Jakate

V. B. Reddy I. J. Miller

Department of Pathology, Rush University Medical Center, 1750 W

Harrison St, Room 570 Jelke, Chicago, IL 60612, USA

e-mail: jamie_m_slade@rush.edu
(RDD), and Erdheim-Chester disease (ECD) among others $[2,3]$. $\mathrm{LCH}$ is a neoplasm of antigen presenting cells (dendritic cells). The cells in ECD are phagocytic histiocytes [4].

Langerhans cell histiocytosis ( $\mathrm{LCH}$ ) is a rare condition that can be encountered in any age group, but is most often diagnosed in childhood. The incidence in adults is estimated to be only one to two cases per million, compared to an incidence of three to five cases of LCH per million children $[5,6]$. Unisystemic LCH (55\% of cases) occurs in patients of any age, each having unifocal or multifocal involvement of a single organ or tissue such as the bone, skin, lymph node, lungs, or central nervous system. Multisystemic disease involves two or more organ systems and carries a worse prognosis [7]. Acute disseminated multisystem disease is most commonly seen in children under 3 years of age. In adults, LCH is frequently a chronic, indolent disease involving a single organ. The most common form of LCH in adults is isolated pulmonary involvement which is strongly associated with cigarette smoking. The usual clinical presentation of LCH in the skin of adults is an erosive rash in the groin and other intertriginous sites resembling a candida diaper rash, or it can involve the scalp and be mistaken for seborrheic dermatitis $[6,8,9]$. When multiple organ systems are affected, the most commonly involved organs in adults are the lungs, skin, axial skeleton, skull, and pituitary gland [8]. $B R A F^{\mathrm{V} 600 \mathrm{E}}$ mutations have been found in $57 \%$ of LCH cases [10]. Recently, Brown et al. reported the mutually exclusive activating somatic $B R A F \mathrm{~V} 600 \mathrm{E}$ and MAP2Klgene mutations in LCH [11].

ECD is a rare non-LCH first reported by the Austrian pathologist Jakob Erdheim and the American pathologist William Chester [12]. In 1930, Chester described a "lipoid granulomatosis" in the bone, visceral organs, and fat in two middle-aged patients [13]. Forty years later, Henry Jaffe reported a similar case and introduced the eponym "ErdheimChester disease" [14]. Since then, several hundred cases have been reported in the literature. 
ECD is an unusual systemic condition most commonly involving the bone, skin, lung, heart, retroperitoneum, pituitary, and less commonly liver and kidney. It has a slight predilection for males, and most patients are middle-aged adults [15]. Patients present with varied symptoms reflecting the distribution and extent of organs involved. About one third are asymptomatic and have an indolent course. Bone pain is the most common initial complaint. Typically, patients present with symmetric sclerotic lesions in the long bones [16]. Prognosis is poor in patients with extraskeletal involvement [2]. Classical radiological findings helpful in diagnosis are retroperitoneal infiltration with a "hairy kidney" and "coated aorta" appearance [16]. More than half of ECD patients die within 3 years of diagnosis, most commonly of pulmonary or cardiac failure [2]. In one study, $B R A F^{\mathrm{V} 600 \mathrm{E}}$ mutations were detected in 13 of 24 (54\%) cases of ECD [17]. Most recently, Emile et al. discovered 46 of $80(57.5 \%)$ ECD patients with $B R A F$ ${ }^{\mathrm{V} 600 \mathrm{E}}$ mutations as well as an additional $10.9 \%$ of patients with a mutation in PIK3CA and $3.7 \%$ of patients with a mutation in NRAS [18].

Although ECD is rare, its recognition has recently increased, as reflected in the rise in frequency of case reports. Because of its multisystem involvement and insidious presentation, diagnosis can be confounding and may be delayed for many years. Both LCH and ECD can involve multiple organ systems and may be clinically difficult to differentiate from other systemic conditions. These two entities are distinguished from each other by their clinical, radiological, and pathological features. We report an unusual case of a patient who presented with a rash consistent with cutaneous LCH with an atypical pattern of involvement, and over the course of a few months she was found to have ECD involving the bone marrow, as well as a third histiocytosis with a nonspecific immunophenotype in the small intestine, and an underlying myelodysplastic/myeloproliferative neoplasm (MDS/MPN).

\section{Clinical history}

A 61-year-old Caucasian woman with a past medical history of hypertension presented to the dermatology clinic at our hospital with a scalp and truncal rash (Fig. 1a) for the preceding 8 months. Large, pink, scaly, psoriasiform plaques on the scalp, neck, chest, abdomen, back, groin, and gluteal cleft were noted on exam. Her review of systems was significant for a 30-lb unintentional weight loss over the last 9-12 months. Eight months prior to coming to our clinic, she had been diagnosed with LCH based on skin biopsy and treated with PUVA therapy (30 sessions) and topical steroids, which led to some improvement, but was discontinued due to prohibitive cost and nausea from the PUVA.

A repeat punch biopsy at our institution from the abdominal rash showed a superficial dermal infiltrate of histiocytic cells with pagetoid spread into the overlying epidermis (Fig. 1b). The histiocytic cells were positive for CD68, CD1a, and S100 supporting the diagnosis of LCH (Fig. 1c-e). As the patient was unable to tolerate PUVA, she was started on topical steroids, oral prednisone (60 mg daily), and oral methotrexate (10 mg weekly). Within a month of treatment, she developed lower extremity edema with grade 3 ulcers as well as anemia ( $\mathrm{Hb} 9.8 \mathrm{~g} / \mathrm{dL}$ ), thrombocytopenia (platelets $69 \mathrm{th} / \mu \mathrm{L}$ ), and leukocytosis (WBC $75.5 \mathrm{th} / \mu \mathrm{L}$ ) with atypical monocytes noted on her complete blood count. Therefore, methotrexate was held and the dose of prednisone reduced. The patient was referred to the hematology service at another hospital for evaluation of her abnormal laboratory test results. A repeat complete blood count showed leukocytosis (WBC $59.7 \mathrm{th} / \mu \mathrm{L}$ ), anemia ( $\mathrm{Hb} 9.2 \mathrm{~g} / \mathrm{dL}$ ), and thrombocytopenia (platelets $79.9 \mathrm{th} / \mu \mathrm{L}$ ). Bone marrow biopsy and aspirate smears revealed moderately hypercellular marrow with neutrophilic and monocytic hyperplasia and decreased erythropoiesis (myeloid to erythroid ratio of more than 20 to 1 ), as well as single and clustered, large, atypical histiocytes showing erythrophagocytosis and emperipolesis (Fig. 2a-c). These abnormal histiocytes were positive for CD68 and negative for $\mathrm{CD} 1 \mathrm{a}$ and S100. The peripheral blood showed marked neutrophilia $(52.29 \mathrm{th} / \mu \mathrm{L})$ with atypical hypogranular and hypersegmented forms and an absolute monocytosis $(2.62 \mathrm{th} / \mu \mathrm{L})$ with nuclear and cytoplasmic immaturity (Fig. 2d), but no increase in blasts. The red blood cells showed a normocytic, normochromic anemia with mild anisopoikilocytosis. The bone marrow biopsy was reviewed at our institution and a diagnosis of MDS/MPN, likely chronic myelomonocytic leukemia, with associated ECD was rendered.

Three days later, she was admitted to the intensive care unit at our institution for increasing weakness, hypoxic respiratory failure, hypernatremia (sodium $175 \mathrm{meq} / \mathrm{L}$ ), anemia (Hb $9.9 \mathrm{~g} / \mathrm{dL}$ ), thrombocytopenia (platelets $70.0 \mathrm{th} / \mu \mathrm{L}$ ), leukocytosis (WBC $78.0 \mathrm{th} / \mu \mathrm{L}$ ), and signs of sepsis. Her anemia was transfusion-dependent requiring multiple transfusions throughout her course. She was diagnosed with diabetes insipidus and treated with supplemental oxygen, D5W along with desmopressin (DDAVP), and broad spectrum antibiotics. CT scan of the abdomen and pelvis showed enlarged kidneys with mild perinephric fat stranding as well as smooth, long segment soft tissue encasement of the aorta (Fig. 3). These findings are consistent with the classical radiological findings of a "hairy kidney" and "coated aorta" in ECD. Although no complaints of bone pain were reported, a bone scan reported uptake in the distal right femur.

CT scan of the chest showed bilateral diffuse pulmonary reticular nodular thickening, scattered emphysematous changes, and thickening of the intralobular septa. She underwent a bronchoscopy which revealed rare atypical histiocytes and was positive for Pneumocystis jiroveci pneumonia (PJP) for 


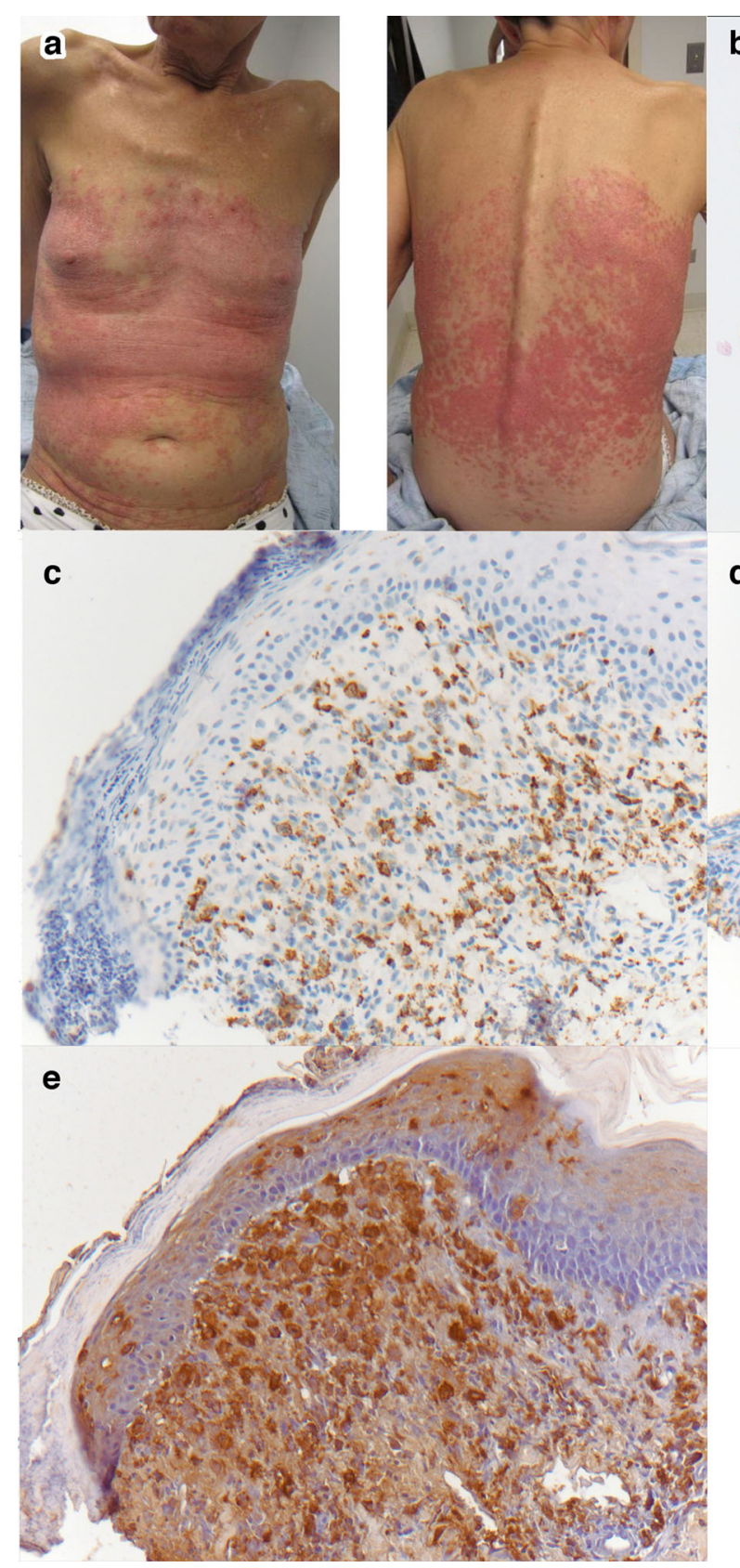

Fig. 1 a Photographs of the truncal rash showing large, pink, and scaly psoriasiform plaques. b Low power magnification of a punch skin biopsy of the left lateral abdomen showing a superficial dermal infiltrate of histiocytic cells with pagetoid spread into the overlying epidermis. The

which trimethoprim/sulfamethoxazole was initiated. Because of her presenting leukocytosis, thrombocytopenia, and anemia, an inpatient hematology consultation was obtained. A repeat bone marrow biopsy was performed which showed similar findings to the previous biopsy. The patient's clinical history of diabetes insipidus, radiographic findings in the aorta and kidneys, and morphologic findings in the bone marrow established a final diagnosis of Erdheim-Chester disease with evidence of an underlying MDS/MPN. The karyotype was normal, and $J A K 2 V 617 F$ mutational analysis and FISH for

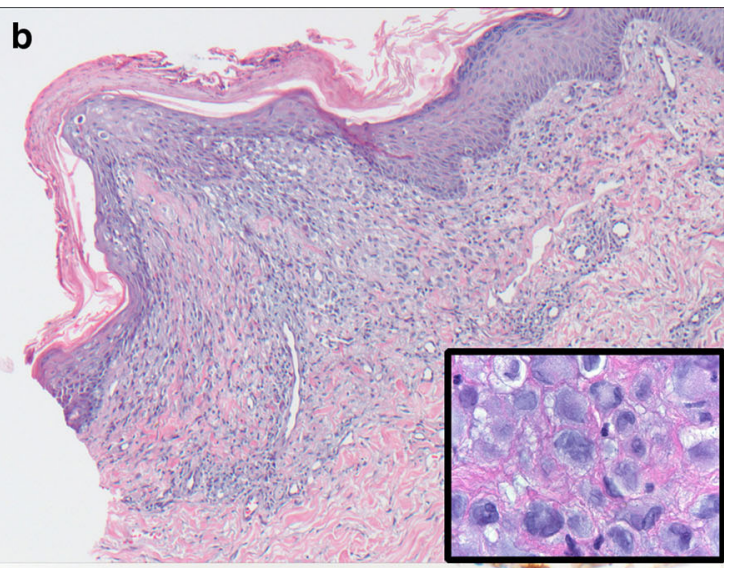

d

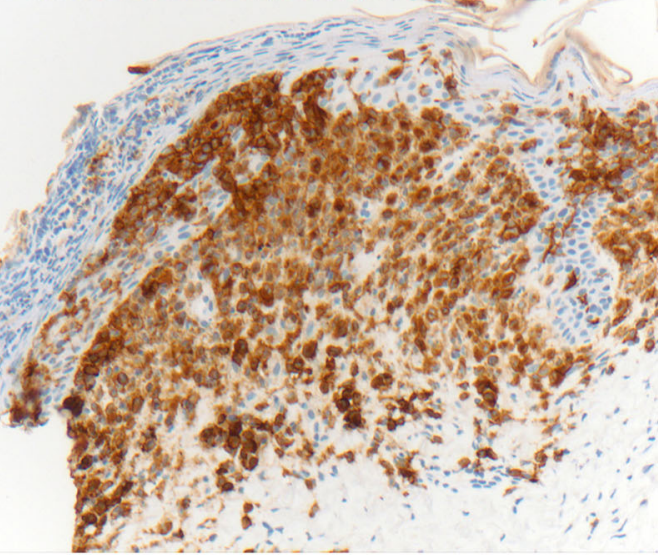

histiocytes showed typical features of Langerhans cells including indented nuclei with moderately abundant, slightly eosinophilic cytoplasm (inset). c The histiocytic cells were positive for CD68, d CD1a, and e S100 supporting the diagnosis of $\mathrm{LCH}$

$B C R / A B L$ translocation were negative. $B R A F^{\mathrm{V} 600 \mathrm{E}}$ gene mutation analysis and immunohistochemical analysis of the bone marrow and duodenum were negative.

Due to the patient's recent onset of nausea, anorexia, and abdominal fullness, an esophagoduodenoscopy (EGD) was performed. Gross findings of the EGD were unremarkable. However, the endoscopic duodenal biopsy revealed an atypical histiocytic infiltration of the submucosa. The histiocytes were positive for $\mathrm{CD} 68$, negative for $\mathrm{CD} 1 \mathrm{a}$, and positive for S100 - an abnormal but nonspecific immunoprofile (Fig. 4). 


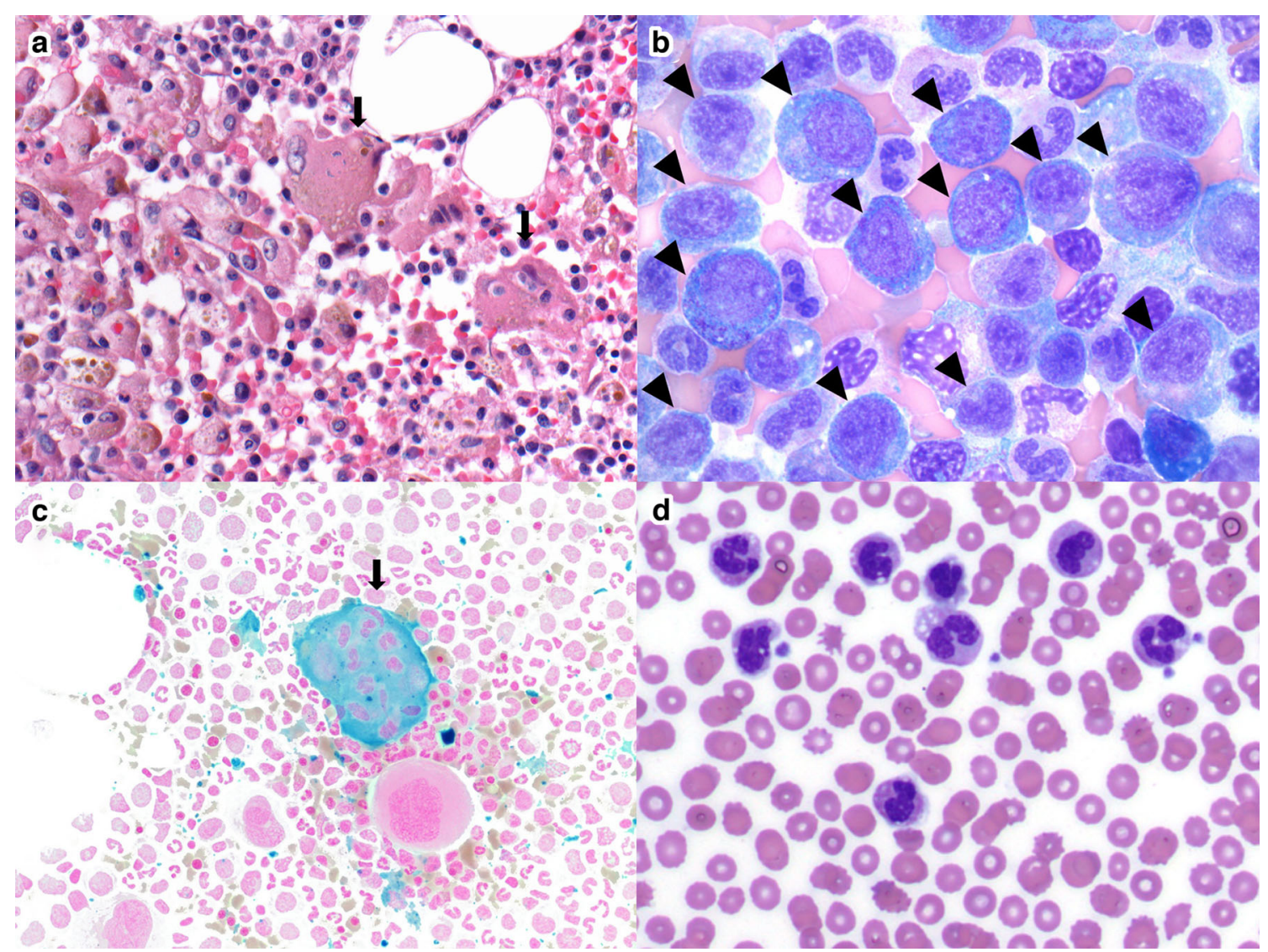

Fig. 2 a Bone marrow biopsy showing an interstitial infiltration of single and clustered large, atypical histiocytes (arrows). b Bone marrow aspirate showing monocytosis (arrowheads) with immaturity with admixed

These histiocytes did not show emperipolesis, as seen in RDD.

The patient was transferred to the hematology service with plans for treatment with IFN-alpha. However, she developed

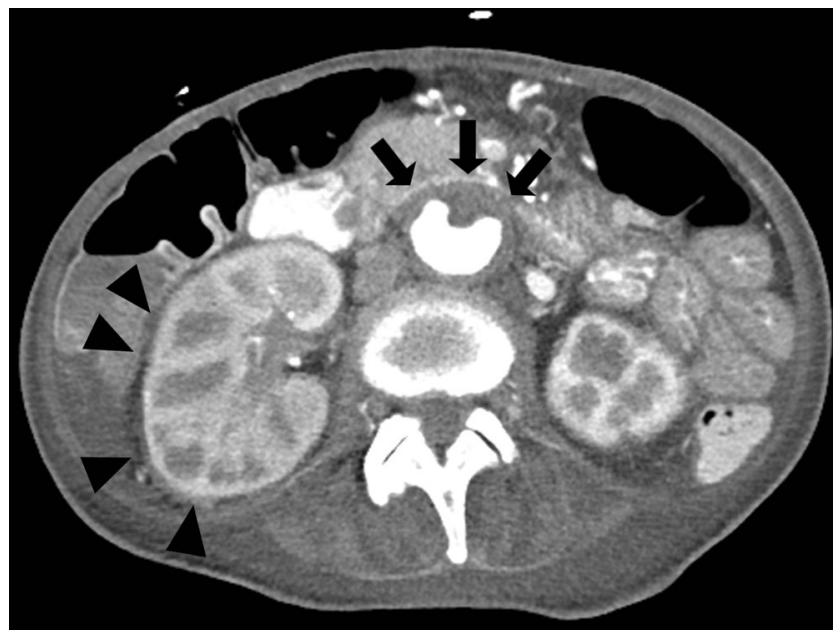

Fig. 3 CT scan displaying classical finding of the appearance of a "hairy kidney" - an irregular border around the kidney due to retroperitoneal infiltration of the perirenal fat (arrowheads) as well as a "coated aorta" showing soft tissue encasement and aneurysmal dilatation of the aorta with an intraluminal thrombus (arrows) neutrophils. c An iron stain showing the emperipolesis of neutrophils (arrow) and occasional lymphocytes. d The peripheral blood showing neutrophilia

systemic toxicities with 5 doses of IFN-alpha and could not tolerate further treatment. Her respiratory function worsened, and she developed bowel obstruction and became severely malnourished. She died within a month after being diagnosed with ECD.

\section{Discussion}

We presented here a case of a 61-year-old woman who succumbed to multisystemic involvement by three different histiocytic proliferations with distinct morphologies and immunophenotypes, and evidence of an underlying MDS/ MPN. Cases of LCH and concurrent non-LCH disorders, specifically RDD or ECD have been reported. We found 12 cases in the English literature of concurrent LCH and RDD [19-22]. The majority of these cases had a predominance of RDD with a lesser component of LCH and with occurrence of both diseases in the same affected organ. Only one of the 12 cases exhibited concomitant RDD and LCH in different anatomical locations [22].

A total of 45 cases of concurrent LCH and ECD, including our present case, have been found (Table 1). The patients' ages 


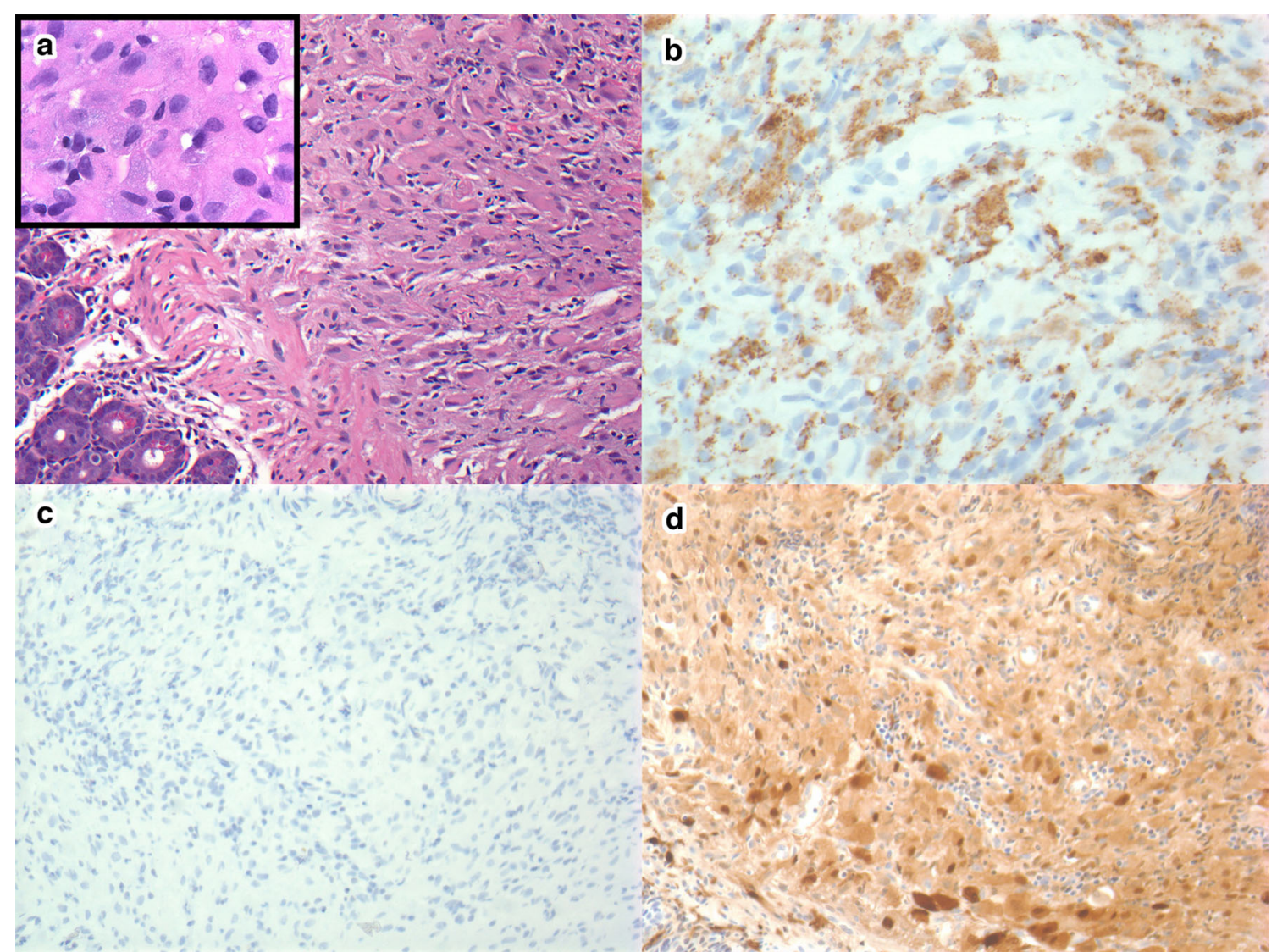

Fig. 4 a H\&E of a duodenal biopsy showing submucosal infiltration by a dense sheet of abnormal histiocytes. The histiocytes were medium-sized with abundant foamy cytoplasm, some with indented nuclei (inset). b Immunostain for CD68 highlights the histiocytic infiltrate. c
Immunostain for $\mathrm{CD} 1 \mathrm{a}$ is negative and $\mathbf{d}$ positive for $\mathrm{S} 100$ - an abnormal but nonspecific immunoprofile for Erdheim-Chester disease and Langerhans cell histiocytosis ranged from 2 to 75 years with a median age of 43 in 23 cases reported by Hervier et al. [40] and a mean age of 45 years in the remaining 22 cases. There was no evident gender bias (F:M of 25:20) . All 45 cases were biopsy proven diagnoses of LCH. Thirty-six of 45 cases were biopsy proven diagnoses of ECD with the remaining nine cases diagnosed based on radiologic findings $[24,25,31,38,40]$. Complete blood counts, which were provided in five cases, excluding our current case, showed a mild to moderate anemia in all five cases $[25,28,31,35,36]$. There were no reports of monocytosis or neutrophil dysplasia in any of the remaining cases to raise suspicion of a MDS/MPN, as seen in our patient. LCH involving the skin was present in 20 cases, excluding our current case. The majority of the cases of cutaneous LCH were described as ulcerative lesions involving the intertriginous areas, vulva, scalp, and thighs. In contrast, our patient had an unusual presentation of LCH with large, pink, scaly, and psoriasiform plaques on the trunk and scalp.

The largest series of concurrent LCH and ECD cases (termed "mixed histiocytosis") was recently reported in 23 patients by Hervier et al. The study compared the phenotype of patients with concurrent $\mathrm{LCH}$ and ECD to that of patients with isolated LCH and isolated ECD and found that the phenotype of patients with mixed histiocytosis was closer to that of isolated ECD than to isolated LCH. Additionally, Hervier et al. indicated that the association of LCH and ECD is linked to the $B R A F^{\mathrm{V} 600 \mathrm{E}}$ mutation which was identified in $9(82 \%)$ of $11 \mathrm{ECD}$ lesions and in $11(69 \%)$ of $16 \mathrm{LCH}$ lesions [40]. Haroche et al. investigated the frequency of $B R A F^{\mathrm{V} 600 \mathrm{E}} \mathrm{mu}-$ tations in different types of histiocytoses including ECD, LCH, Rosai-Dorfman disease, juvenile xanthogranuloma, histiocytic sarcoma, xanthoma disseminatum, interdigitating dendritic cell sarcoma, and necrobiotic xanthogranuloma. They detected $B R A F^{\mathrm{V} 600 \mathrm{E}}$ mutations in 13 of $24(54 \%)$ cases of ECD and 11 of 29 (38\%) cases of LCH, but none in the other histiocytoses [17]. Additionally, Emile et al. discovered 46 of $80(57.5 \%)$ ECD patients with $B R A F^{\mathrm{V} 600 \mathrm{E}}$ mutations as well as an additional $10.9 \%$ of patients with a mutation in PIK3CA and $3.7 \%$ of patients with a mutation in NRAS [18]. In another study, Badalian-Very et al. [10] identified $B R A F^{\mathrm{V} 600 \mathrm{E}}$ mutations in 35 of $61(57 \%)$ cases of $\mathrm{LCH}$. More recently, Brown et al. reported the mutually exclusive activating somatic $B R A F \mathrm{~V} 600 \mathrm{E}$ and $M A P 2 K 1$ gene mutations in LCH [11]. Immunomorphological features also 


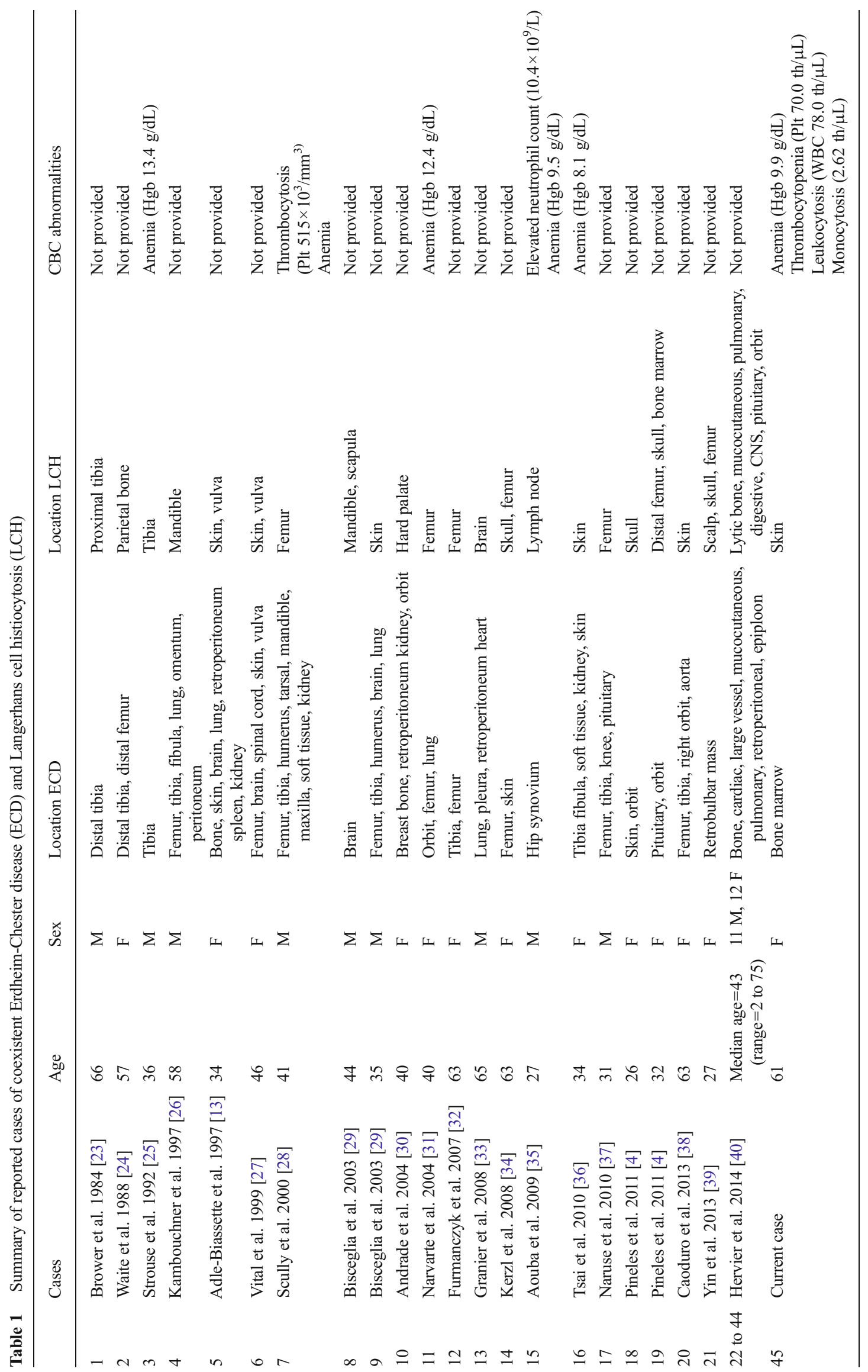


suggest overlapping pathogenesis of the histiocytoses. A subset of cases with combined RDD and LCH found in a lymph node showed rare transitional cells with morphologic features of RDD but with immunohistochemical features of LCH cells (CD1a and langerin expression) [21]. In our present case, the histiocytes found in the duodenum had morphologic features of ECD but immunohistochemical features of $\mathrm{LCH}$, while the abnormal marrow histiocytes showed emperipolesis-like RDD but lacked S100 expression. The various histiocytoses are considered to be proliferations of differentiated cells. Cases with multiple lineages may represent proliferations of less committed tumor stem cells.

Our case likely represents the end of the spectrum with origin in the marrow hematopoietic stem cell. There have been several case reports of patients with LCH developing a second hematological malignancy, such as MDS and MDS/MPN either prior to, concurrent with, or subsequent to their LCH diagnosis [41-49]. Iwasaki et al. recently reported an 82-year-old male with cutaneous LCH who died from chronic myelomonocytic leukemia (CMML) diagnosed 10 months later and identified 37 cases of LCH with a coexistent hematological malignancy reported between 2000 and 2013 [42]. The most common malignancies identified were lymphoblastic leukemia (ALL) in 11 patients, MDS in 8 patients, and acute myeloid leukemia (AML) in 8 patients, and included CMML in 3 patients and juvenile myelomonocytic leukemia (JMML) in 1 patient. Eleven of the 15 patients with skin-limited LCH and known outcome had a fatal course. Yohe et al. described four cases of concurrent or subsequent LCH in patients with acute leukemia of ambiguous or myeloid lineage [41]. In the two cases successfully tested, they did not find a $B R A F^{\mathrm{V} 600 \mathrm{E}}$ mutation. However, none of their cases had skin involvement. Edelbroek et al. noted a frequent association between $\mathrm{LCH}$ presenting in the skin in adults and a second hematological malignancy [43]. In 18 patients presenting to their hospitals with an initial diagnosis of cutaneous LCH, 5 developed hematological malignancies, including myelomonocytic leukemia (2 cases), histiocytic sarcoma (1 case), diffuse large B-cell lymphoma ( 1 case), and peripheral T-cell lymphoma (1 case). Their literature review revealed 74 adult patients presenting with cutaneous LCH between 1974 and 2011, of which 6 had a second hematological malignancy. The pathophysiological link between LCH and increased risk of hematological malignancy remains unclear. Given the frequency of secondary tumors of myelomonocytic origin, it has been speculated that $\mathrm{LCH}$ and these neoplasms develop from a common bone marrow precursor that may follow different paths of differentiation [43]. Chromosome 7 abnormalities have been documented in $\mathrm{LCH}$, MDS, and AML [42, 45, 46], and clonal gene rearrangement of the T-cell receptor $\gamma$-chain has been detected in concurrent lesions of LCH and T-cell derived leukemia, suggesting more than just a chance correlation.
Histiocytic proliferations in association with MDS/MPN parallel other clonal lineage outgrowths, such as mastocytosis and plasmacytoid dendritic cell neoplasms, that can accompany a myeloproliferative neoplasm. For example, mastocytosis may be limited to the skin in cutaneous mastocytosis, most commonly urticaria pigmentosum, or may manifest as systemic mastocytosis, most commonly involving the bone marrow or gastrointestinal tract. In up to $30 \%$ of cases of systemic mastocytosis, an associated hematological clonal non-mast cell disorder (AHNMD) occurs, predominantly myeloid neoplasms and most commonly chronic myelomonocytic leukemia [50]. Also, blastic plasmacytoid dendritic cell neoplasm, derived from the precursors of plasmacytoid dendritic cells, can occur as an isolated disease most frequently involving the skin and bone marrow, or may occur in the context of another hematologic neoplasm. Approximately 10 to $20 \%$ of cases are associated with hematologic malignancies such as myelodysplastic syndrome, chronic myeloid leukemia, chronic myelomonocytic leukemia, and acute myeloid leukemia [50]. Furthermore, in patients with chronic myelomonocytic leukemia, nodal proliferations of plasmacytoid dendritic cells (originally called plasmacytoid T or "T-zone" cells, and then plasmacytoid monocytes), have been recognized for over two decades [51-54]. Interestingly, when the skin is involved in CMML, about half the cases have infiltrates showing plasmacytoid dendritic cell lineage [55].

The chronic, indolent nature of LCH in adults begs the question of whether LCH in adults may be more generally associated with unrecognized marrow stem cell abnormalities.

Acknowledgments We thank Gladys Macagba, D.O., Jorge Novo, M.D., and Maria Martin, M.D., for their contributions.

Conflict of interest The authors declare that they have no conflict of interest.

\section{References}

1. Kapur P, Erickson C, Rakheja D, Carder KR, Hoang MP (2007) Congenital self-healing reticulohistiocytosis (Hashimoto-Pritzker disease): ten-year experience at Dallas Children's Medical Center. J Am Acad Dermatol 56(2):290-4

2. Veyssier-Belot C, Cacoub P, Caparros-Lefebvre D, Wechsler J, Brun B, Remy M, Wallaert B, Petit H, Grimaldi A, Wechsler B, Godeau P (1996) Erdheim-Chester disease. Clinical and radiologic characteristics of 59 cases. Medicine 75(3):157-169

3. Mazor et al. (2007) Erdheim-Chester disease: a comprehensive review of the literature. Orphanet J Rare Dis 2013; 8-137. In: Nakasu $\mathrm{S}$, Tsufi A, Fuse I, Hirai H: Intracranial solitary juvenile xanthogranuloma successfully treated with stereotactic radiosurgery. J Neuroncol; 84:99-102

4. Pineles S, Liu G, Acebes X, Arruga J, Nasta S, Glaser R, Pramick M, Fogt F (2011) Presence of Erdheim-Chester disease and Langerhans cell histiocytosis in the same patient: a report of 2 cases. J NeuroOphthalmol 31:217-223 
5. Carstensen H, Ornvold K (1993) The epidemiology of Langerhans cell histiocytosis in children in Denmark, 1975-89. Med Pediatr Oncol 21:387-388

6. Baumgartner I, von Hochstetter A, Baumert B, Luetolf U, Follath F (1997) Langerhans'-cell histiocytosis in adults. Med Pediatr Oncol 28:9-14

7. Minkov M (2011) Multisystem Langerhans cell histiocytosis in children: current treatment and future directions. Pediatr Drugs 13(2):7586

8. Fichter J, Doberauer C, Seegenschmiedt H (2007) Langerhans cell histiocytosis in adults: an interdisciplinary challenge. Dtsch Arztebl; 104(34-35):A 2347-53

9. Malpas JS, Norton AJ (1996) Langerhans cell histiocytosis in the adult. Med Pediatr Oncol 27:540-546

10. Badalian-Very G et al (2010) Recurrent BRAF mutations in Langerhans cell histiocytosis. Blood 116(11):1919-1923

11. Brown NA, Furtado LV, Betz BL, Kiel MJ, Weigelin HC, Lim MS, Elenitoba-Johnson KS (2014) High prevalence of somatic MAP2K1 mutations in BRAF V600E-negative Langerhan cell histiocytosis. Blood 124(10):1655-8

12. Über CW (1930) Lipoidgranulomatose. Virchows Arch Pathol Anat 279:561-602

13. Adle-Biassette H, Chetritt J, Bergemer-Fouquet A, Wechsler J, Mussini J, Gray F (1997) Pathology of the central nervous system in Chester-Erdheim disease: report of three cases. J Neuropathol Exp Neurol 56(11):1207-16

14. Jaffe HL (1972) Metabolic, degenerative and inflammatory disease of bone and joints. Lea \& Febiger, Philadelphia; 535-41

15. Drier et al (2010) Cerebral, facial, and orbital involvement in Erdheim-Chester disease: CT and MR imaging findings. Radiology 255(2):586-94

16. Cavalli G, Guglielmi B, Berti A et al (2013) The multifaceted clinical presentations and manifestations of Erdheim-Chester disease: comprehensive review of the literature and of 10 new cases. Ann Rheum Dis 72:1691-1695

17. Haroche $\mathrm{J}$ et al (2012) High prevalence of BRAF V600E mutations in Erdheim-Chester disease but not in other non-Langerhans cell histiocytoses. Blood 120(13):2700-2703

18. Emile JF, Diamond EL, Helias-Rodzewicz Z, Cohen-Aubart F, Charlotte F, Hyman DM, Kim E, Rampal R, Patel M, Ganzel C, Aumann S, Faucher G, Le Gall C, Leroy K, Colombat M, Kahn JE, Trad S, Nizard P, Donadieu J, Taly V, Amoura Z, Abdel-Wahab O, Haroche J (2014) Recurrent RAS and PIK3CA mutations in Erdheim-Chester disease. Blood 124(19):3016-3019

19. Wang KH, Cheng CJ, Hu CH, Lee WR (2002) Coexistence of localized Langerhans cell histiocytosis and cutaneous Rosai-Dorfman disease. Br J Dermatol 147:770-774

20. Sachdev R, Shyama J (2008) Co-existent Langerhans cell histiocytosis and Rosai-Dorfman disease: a diagnostic rarity. Cytopathology 19(1):55-58

21. O'Malley DP et al (2010) Co-occurrence of Langerhans cell histiocytosis and Rosai-Dorfman disease: possible relationship of two histiocytic disorders in rare cases. Mod Pathol 23:1616-1623

22. Cohen-Barak E, Rozenman D, Schafer J, Krausz J et al (2013) An unusual co-occurrence of Langerhans cell histiocytosis and RosaiDorfman disease: report of a case and review of the literature. Int $\mathbf{J}$ Dermatol. doi:10.1111/ijd.12051

23. Brower AC, Worsham GF, Dudley AH (1984) Erdheim-Chester disease: a distinct lipoidosis or part of the spectrum of histiocytosis? Radiology 151(1):35-38

24. Waite R, Doherty P, Liepman M, Woda B (1988) Langerhans cell histiocytosis with the radiographic findings of Erdheim-Chester disease. Am J Radiol 150:869-871

25. Strouse P, Ellis B, Shifrin L, Shah A (1992) Case report 710. Skeletal Radiol 21:64-67
26. Kambouchner M, Colby TV, Domenge C, Battesti JP, Soler P, Tazi A (1997) Erdheim-Chester disease with prominent pulmonary involvement associated with eosinophilic granuloma of the mandibular bone. Histopathology 30(4):353-358

27. Vital C, Bioulac-Sage P, Tison F, Rivel J, Begueret H, Gomez C, Leaute-Labreze C, Diard F, Vital A (1999) Brain stem infiltration by mixed Langerhans cell histiocytosis and Chester-Erdheim disease: more than just an isolated case? Clin Exp Path 47:71-76

28. Scully R, Mark EJ, McNeely WF, Ebeling SH, Phillips LD, Ellender SM (2000) Case records of the Massachusetts General Hospital, weekly clinicopathological exercises, case 9-2000: a 41 year old man with multiple bony lesions and adjacent soft-tissue masses. $\mathrm{N}$ Engl J Med 342:875-883

29. Bisceglia M, Cammisa M, Suster S, Colby T (2003) Erdheim-Chester disease: clinical and pathological spectrum of four cases from the Arkadi M. Rywlin Slide seminars. Adv Anat Pathol 10(3):160-71

30. Andrade VP, Nemer CCC, Prezotti ANL, Goulart WSL (2004) Erdheim-Chester disease of the breast associated with Langerhanscell histiocytosis of the hard palate. Virchows Arch 445(4):405-409

31. Narvarte S, Sanjurjo N, Rodriguez G, Badiola A (2004) ErdheimChester disease and Langerhans histiocytosis. A fortuitous association? An Med Interna 21(12):593-596

32. Furmanczyk P, Bruckner J, Gillespie T, Rubin B (2007) An unusual case of Erdheim-Chester disease with features of Langerhans cell histiocytosis. Skeletal Radiol 36:885-889

33. Granier M, Micheau A, Serre I (2008) A rare cause of cardiac tumour: an Erdheim-Chester disease with cardiac involvement co-existing with an intracerebral Langerhans cell histiocytosis. Eur Heart J 29(16):1929

34. Kerzl R, Eyerich K, Eberlein B et al (2009) Parallel occurrence of Erdheim-Chester disease and eosinophilic granuloma in the same patient. J Eur Acad Dermatol Venereol 23(2):224-6

35. Aouba A, Larousserie F, Le Guern V, Martin A, Guillevin L (2009) Spumous histiocytic oligoarthritis coexisting with systemic Langerhans cell histiocytosis: case report and literature review. Joint Bone Spine 76(6):701-704

36. Tsai JW, Tsou JH, Hung LY, Wu HB, Chang KC (2010) Combined Erdheim-Chester Disease and Langerhans cell histiocytosis of skin are both monoclonal: a rare case with human androgen-receptor gene analysis. J Am Acad Dermatol 63:284-291

37. Naruse H, Shoda H, Okamoto A, Oka T, Yamamoto K (2010) A case of osteoarthropathy due to Erdheim-Chester disease with overlapping Langerhans' cell infiltration. Inter Med 49:1225-1228

38. Caoduro C, Ungureanu CM, Rudenko B, Angoue O, Blagosklonov O, Paycha F, Boulahdour H (2013) 18F-fluoride PET/CT aspect of an unusual case of Erdheim-Chester disease With histologic features of Langerhans cell histiocytosis. Clin Nucl Med 38:541-542

39. Yin J, Zhang F, Zhang H, Shen L, Li Q, Hu S, Tian Q, Bao Y, Jia W (2013) Hand-Schuller-Christian disease and Erdheim-Chester disease: coexistence and discrepancy. Oncologist 18:19-24

40. Hervier B et al (2014) Association of both Langerhans cell histiocytosis and Erdheim-Chester disease linked to the $B R A F^{\mathrm{V} 600 \mathrm{E}}$ mutation. Blood 124(7):1119-1126

41. Yohe S, Chenault C, Torlakovic E, Asplund S, McKenna R (2013) Langerhans cell histiocytosis in acute leukemias of ambiguous or myeloid lineage in adult patients: support for a possible clonal relationship. Mod Pathol 27(5):651-6

42. Iwasaki T, Takahashi I, Nagashima T, Igawa S, Komatsu S, Honma M, Ishida-Yamamoto A, Iizuka H (2014) Cutaneous Langerhans cell histiocytosis in elderly with chronic myelomonocytic leukemia. J Dermatol 41:262-265

43. Edelbroek JR, Vermeer MH, Jansen PM, Stoof TJ, van der Linden MMD, Horvath B, van Baarlen J, Willemze R (2012) Br J Dermatol 167(6):1287-94

44. Kaiserling E, Horny HP (1988) Dermal Langerhans' cell tumor in chronic myelomonocytic leukemia. Ultrastruct Pathol 12(2):209-19 
45. Billings S, Hans C, Schapiro B, Martin R, Fivenson D, Fruland J, Moores W, Cotton J (2006) Langerhans cell histiocytosis associated with myelodysplastic syndrome in adults. J Cutan Pathol 33:171-174

46. Mahoney DH, McClain KL, Hanson IC, Taylor LD, Steuber CP (1989) Acquired immune deficiency, myelodysplasia, and acute nonlymphocytic leukemia associated with monosomy 7 and $t(3 ; 3)$ (q21;q26) in a child with Langerhans cell histiocytosis. Am J Pediatr Hematol Oncol Summer 11(2):153-7

47. Hammami H, Zaraa I, El Euch D, Chelly I, Haouet S, Mokni M, Ben Osman A (2010) Letterer-Siwe disease associated with chronic myelomonocytic leukemia: a fortuitous association? Acta Dermatoven Alp Pannonica Adriat 19(1):45-8

48. Kager L, Heise A, Minkov M, Mobius D, Kotte W, Schulte-Overberg U, Henze G, Gadner H (1999) Occurrence of acute nonlymphoblastic leukemia in two girls after treatment of recurrent, disseminated Langerhans cell histiocytosis. Pediatr Hematol Oncol 16(3):251-6

49. Surico G, Muggeo P, Rigillo N, Gadner H (2000) Concurrent Langerhans cell histiocytosis and myelodysplasia in children. Med Pediatr Oncol 35(4):421-5
50. Swerdlow SH, Campo E, Harris NL et al. eds (2008) World Health Organization classification of tumours of haematopoietic and lymphoid tissues. Lyon: IARC: $54-63,145-147$

51. Horny HP et al (1995) Evidence for a lymphotropic nature of circulating plasmacytoid monocytes: findings from a case of CD56+ chronic myelomonocytic leukemia. Eur J Haematol 54(4):209-16

52. Facchetti F, De Wolf-Peeters C, Kennes C, Rossi G, De Vos R, van den Oord JJ, Desmet VJ (1990) Leukemia-associated lymph node infiltrates of plasmacytoid monocytes (so-called plasmacytoid T-cells). Evidence for two distinct histological and immunophenotypical patterns. Am J Surg Pathol 14(2):101-12

53. Baddoura FK, Hanson C, Chan WC (1992) Plasmacytoid monocyte proliferation associated with myeloproliferative disorders. Cancer 69(6): 1457-67

54. Harris NL, Demirjian Z (1991) Plasmacytoid T-zone cell proliferation in a patient with chronic myelomonocytic leukemia. Histologic and immunohistologic characterization. Am J Surg Pathol 15(1):87-95

55. Vitte F et al (2012) Specific skin lesions in chronic myelomonocytic leukemia: a spectrum of myelomonocytic and dendritic cell proliferations: a study of 42 cases. Am J Surg Pathol 36(9):1302-16 